\title{
Comparison of Simulation-Based versus Live Tissue-Based Ocular Trauma Training on Novice Ophthalmologists: Repair of Marginal Eyelid Laceration Model
}

\author{
Sean Sykes, DO ${ }^{1,2}$ Eva Chou, MD ${ }^{1,2}$ Robert A. Mazzoli, MD, FACS 3 Joseph Pasternak, MD ${ }^{1,2}$ \\ Denise Ryan, $\mathrm{MS}^{3}$ Rose Sia, MD ${ }^{3}$ Marcus Colyer, MD ${ }^{1,2}$
}

1 Ophthalmology Service, Walter Reed National Military Medical Center, Bethesda, Maryland

2 Department of Surgery, Uniformed Services University of the Health Sciences, Bethesda, Maryland

${ }^{3}$ Vision Center of Excellence, Walter Reed National Military Medical Center, Bethesda, Maryland

Journal of Academic Ophthalmology 2018;10:e61-e68.

\author{
Address for correspondence Sean Sykes, DO, Walter Reed National \\ Military Medical Center, Ophthalmology Residency Program, \\ 8901 Rockville Pike, Bethesda, MD 20889 \\ (e-mail: sean.e.sykes.mil@mail.mil).
}

\begin{abstract}
Keywords

- ophthalmology

- simulation

- training

Introduction Simulation training in medical education provides the ability to teach valuable surgical skills in an environment free of risk to patients. Surgical simulation in ophthalmology continues to evolve as new technologies advance, though widespread use in ophthalmology outside of cataract surgery simulation is lacking. Here, we present a study into the efficacy of surgical simulation for eyelid laceration repair when compared with standard tissue-based instruction.

Materials and Methods The study included 43 ophthalmology residents and 16 staff ophthalmologists from the Ocular Trauma Surgery Laboratory (OTSL) at the Uniformed Services University of the Health Sciences (USUHS). After initial evaluation on their ability to repair marginal eyelid lacerations on a porcine eye, residents were randomized to receive training in marginal eyelid repair technique from faculty preceptors using either traditional porcine tissue or the Ocular and Craniofacial Trauma Treatment Training System (Medical Device and Simulation Laboratory). They were then reevaluated after training. Participating staff also underwent initial evaluation, self-guided training, and post-training evaluation. Outcome measures included successful repair of laceration, number of sutures required to close a $10-\mathrm{mm}$ wound, time required to repair, and the following graded on a scale of 1-4 (1-poor, 2-fair, 3-good, 4-excellent): tarsal plate reconstruction and margin approximation.

Results Among residents, improved scores in marginal approximation were noted after training when comparing scores both within the simulator-trained group (pre-training score: 2.0, post-training score: 3.0; $p=0.03$ ) and between the simulator (SIM) and live tissue (LIVE) groups (SIM: 3.0, LIVE: $2.0 p=0.03$ ). Neither residents nor staff demonstrated significant differences between SIM versus LIVE in other metrics evaluated. Response in a post-study survey was favorable to simulator training, with $79 \%$ noting the simulator was helpful in teaching skills, and $83 \%$ noting they would use the simulator again.
\end{abstract}

received

November 28, 2017 accepted after revision April 9, 2018
DOI https://doi.org/

$10.1055 / \mathrm{s}-0038-1653972$. ISSN 2475-4757.
Copyright $\odot 2018$ by Thieme Medical Publishers, Inc., 333 Seventh Avenue, New York, NY 10001, USA. Tel: +1(212) 584-4662.
License terms

(ㄷ) (i) $\ominus$ (5) 
Conclusion Simulator technology for teaching marginal eyelid laceration repair appears to be noninferior to traditional tissue-based instruction. Additionally, it appears to be superior when evaluating the ability to approximate the eyelid margin appropriately. Simulators are safe and ethical alternatives to tissue-based instruction, and are favorably received among trainees, and therefore warrant additional investigation and development for ophthalmic surgical training.

Training in surgical repair of ocular trauma is of utmost importance to the ophthalmologist. This is true in the civilian world, but of even more critical importance in the deployed military ophthalmologist. Data suggest involvement of the eye is relatively commonplace in traumatic incidents. Twenty-six percent of survivors of the terrorist attack on the World Trade Center in New York City in 2001 and 8\% of survivors of the Oklahoma City bombing in 1995 sustained ocular injuries. ${ }^{1,2}$ Among the military population, ocular injuries accounted for the fourth most common injury during Operation Iraqi Freedom and Operation Enduring Freedom. ${ }^{3}$ The most frequently encountered ocular injuries included lid and brow lacerations, open globe injuries, and orbital fractures.

Training in techniques to repair such injuries has typically been accomplished with the use of animal tissue models. Porcine eye and adnexal tissue have been demonstrated to be histologically similar to human eye tissue and generally suitable for surgical training. ${ }^{4}$ However, histologic similarity does not necessarily correlate directly with fidelity to human tissue, particularly in anatomic similitude and tissue characteristics. This applies not just to the eyelid but also to globe models as well. Advances in surgical simulation systems in the last several years have allowed training physicians the opportunity to hone skills in a simulated environment, without the risk of injury to patients, or the reliance on living tissue to facilitate training. ${ }^{5,6}$ Ideally, the most desirable feature should be high simulator-to-human similarity, which is a goal of simulation training. As the Department of Defense has directed the reduction in use of animals for medical education training when "alternative methods produce scientifically or educationally valid or equivalent results,"7 simulation-based systems have become increasingly necessary as alternate training platforms. Studies into the effectiveness of surgical simulators in phacoemulsification training for resident physicians have previously demonstrated improvements in speed of skill progression, and decreased errant capsulorrhexis rates. ${ }^{8,9}$ Here, we describe a study into the efficacy of one such simulation system in comparison to living tissue models in training of repair to marginal eyelid lacerations.

\section{Methods}

The Uniformed Services University of the Health Sciences (USUHS) Institutional Review Board (IRB), USUHS Institutional Animal Care and Use Committee and the United States
Army Medical Research and Material Command IRB reviewed and approved the study prior to initiation.

The study comprised novice surgeons training in military and civilian ophthalmology residency programs, as well as board-certified and board-eligible ophthalmologists, all chosen from a convenience sample of residents and staff physicians taking part in the annual Tri-Service Ocular Trauma Surgery Laboratory (OTSL) over a period of 3 years. The OTSL is an annual training course for military ophthalmologists incorporating didactic, Socratic, and hands-on methods to teach established strategies for diagnosing and treating ocular trauma. In each of the 3 years, half of the participating residents were randomly assigned to receive training in surgical repair of either eyelid margin lacerations or corneal lacerations (-Fig. 1). In this article, we focus on data pertaining to those in the eyelid repair group, as the corneal trial is ongoing. Residents $(n=43)$ were second- and third-year ophthalmology residents, whereas staff physicians $(n=16)$ were either general comprehensive ophthalmologists or subspecialty trained and certified in oculoplastic surgery. Staff physicians taking part were evaluated in the second and

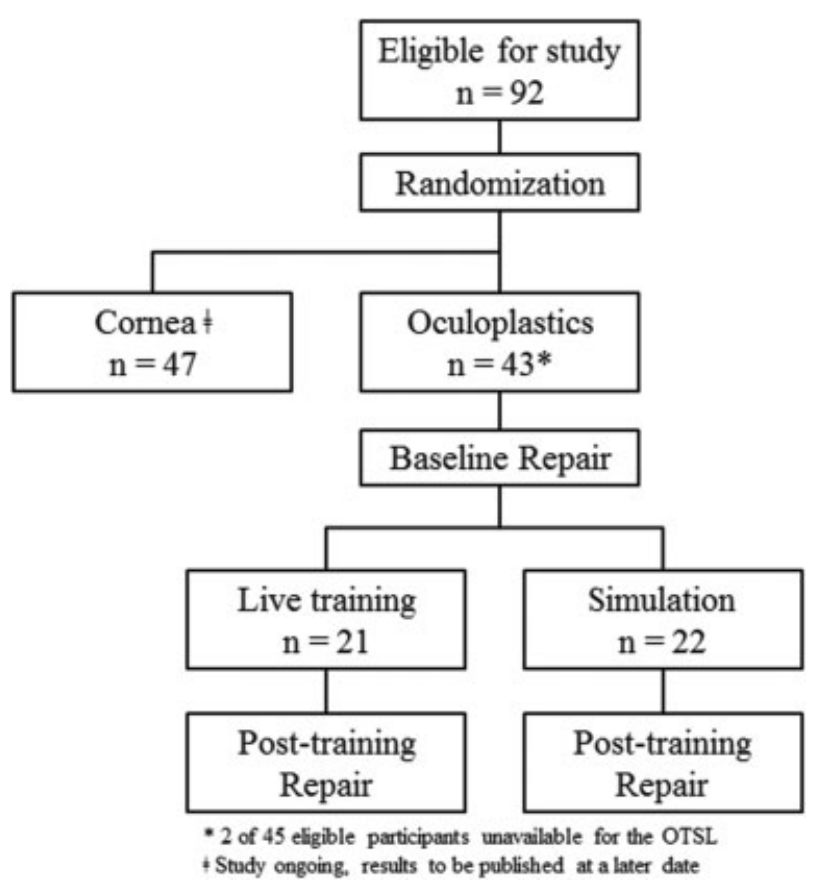

Fig. 1 Resident study structure, years 1-3. 
third years of the study in an effort to evaluate simulator effect on skill level of presumed expert surgeons.

Participants performed an initial evaluation of surgical skill (before training repair [BTR]) by performing an unassisted repair of a $10-\mathrm{mm}$ linear, full-thickness laceration involving the upper lid margin on an exenterated pig eye model. After BTR time to completion was recorded, resident participants were stratified according to the median time, which was deemed the group's baseline "time required to close wound." This measure served as a surrogate for baseline surgical skill level. Half of each group of residents was randomly allocated using a random number generator to receive instruction via traditional live tissue-based instruction (LIVE, $n=21$ ), or to a surgical simulator (SIM, $n=22$ ). Subjects were graded by three masked observers using the median score as the final score for analysis on several metrics. Residents then received instruction limited to 90 minutes while using either traditional LIVE materials or SIM material. Following the instruction period, residents then repeated the assessment on the pig eye with evaluation of metrics once again (post-training repair [PTR]).

Staff physicians were randomly divided into two groups of eight. Each group consisted of two general ophthalmologists and two oculoplastic fellowship-trained ophthalmologists. Both groups performed BTR. One group randomly received SIM training, while the control group received LIVE training. Each group was then assessed again for their PTR results using the same metrics as for the resident group.

\section{Materials}

Training for repair of marginal eyelid lacerations took place on either a traditional animal tissue model (LIVE) or a surgical simulator (SIM). LIVE training was accomplished using swines (Sus scrofa domestica), male or female, weighing 35 to $50 \mathrm{lb}$. Each animal was placed under general anesthesia and maintained under a surgical plane of anesthesia for the entire duration of the procedure. Animals were positioned and a retrobulbar block (1:1 mixture of $2 \%$ lidocaine and $0.75 \%$ bupivacaine) was performed prior to the procedure. Two percent (2\%) lidocaine with 1:100,000 epinephrine was injected into the eyelid for hemostasis and a $10-\mathrm{mm}$ full-thickness superior eyelid laceration was created. Students were then instructed by staff prior to and during the surgical repair with regard to proper preparation and technique. Participants selected to receive training with a surgical simulator used the Ocular and Craniofacial Trauma Treatment Training System (Medical Device and Simulation Laboratory [formerly Simulation Group] at Massachusetts General Hospital, Boston, MA). The Ocular and Craniofacial Trauma Treatment Training System is a silicone-based mannequin simulator based on physically accurate anatomy and uses authentic surgical instruments to repair typical eyelid wounds. The device is composed of a mannequin head with replaceable eye and lid modules ( - Fig. 2). It uses optical and magnetic tracking systems to record instrument and hand motions, and algorithms to compare user performance with reference expert gestures. The simulator is fully developed to simulate eyelid injuries and subsequent repairs. Use of the microscope head is optional; surgical loupes can also be utilized during training. Normative data exist for expert surgeons to allow for direct comparisons. The simulator captures the following output metrics for repairing eyelid lacerations: time of procedure, suture path length, and compactness of motion. Instruction was provided to the individual learners via an oculoplastic-trained ophthalmologist following BTR analysis.
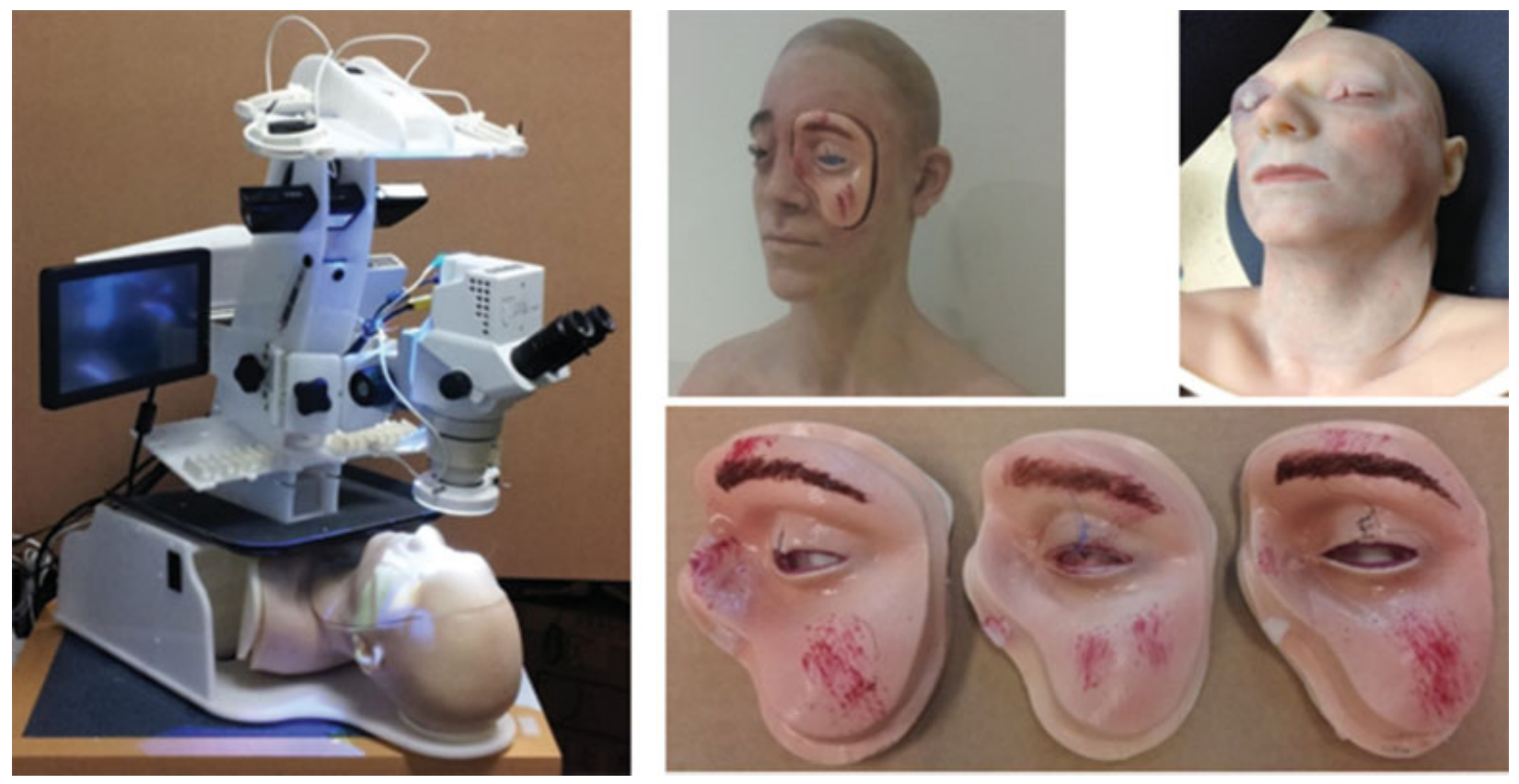

Fig. 2 Ocular and Craniofacial Trauma Treatment Training System with optional microscope attachment. 


\section{Metrics}

Metrics of BTR and PTR analysis included successful repair of the eyelid laceration, number of sutures required to close the laceration, time to repair the wound, tarsal plate reconstruction, and gray line approximation. Successful repair of the laceration was scored as a categorical value, yes or no. Participants either achieved or did not achieve surgically appropriate approximation of the laceration as evaluated by the staff grader. Number of sutures needed to close the laceration was recorded as a discrete ordinal value. While there is no correct number of sutures needed to close any wound, the number of sutures necessary to close a wound is an independent variable in efficacy of a wound closure. More sutures require more time and potentially more variability in other objective measures, while fewer sutures may lead to higher rate of wound reopening and/or increased suture tension, which would cause increased eyelid deformity and loss of function. Time required to repair the laceration was recorded as a continuous variable measured in seconds. This metric is intended to measure a surgeon's efficiency in surgical repair. Tarsal plate reconstruction was graded on an ordinal scale with four grades: $1=$ poor, $2=$ fair, $3=$ good, $4=$ excellent as graded by the course instructors. A poor grade (1) would consist of failure to oppose tarsal tissue from end-to-end. A fair grade (2) would result from a satisfactory repair with an end-to-end repair, but suture pass inconsistency (irregular spacing, irregular depths, etc.) was evident in one or more sutures. A good grade (3) demonstrates satisfactory repair and reveals more than $50 \%$ consistency in suture passes for all sutures placed. An excellent grade (4) demonstrates adequate tarsal plate closure with $100 \%$ consistency in suture passes for all sutures placed. Finally, gray line approximation was measured in a similar fashion to tarsal plate reconstruction as an ordinal scale with four grades: $1=$ poor, 2 = fair, 3 =good, $4=$ excellent as graded by the course instructors. A poor grade (1) demonstrates failure of the student to perform the task. A fair grade (2) reveals success in closing the eyelid skin, but the eyelid edges are not opposed at the eyelid margin. A good grade (3) would consist of appropriate approximation of the gray line, but skin is not opposed on either side. An excellent grade (4) reveals $100 \%$ consistency in suture placement with no noticeable deficiencies and careful approximation of the gray line.

Grading was completed by three independent boardcertified ophthalmologists. Each was provided standard descriptions correlating with each level of repair. Two graders were used as the primary scorers, while the third grader served as a tiebreaker in the event of disparate scoring between graders.

In addition to graded metrics, participants in the course were given a survey to assess level of training, prior simulator experience, and prior surgical experience. Participants were also given a selection of questions to assess their experience with the simulator and its usefulness in training and maintenance of skills.

\section{Results}

\section{Participant Demographics}

Demographics and survey of prior simulator and eyelid repair experience of resident study participants are demonstrated in - Table 1. Between the SIM and LIVE groups, gender, age, and number of prior eyelid repairs were largely similar among residents. However, simulator experience was variable between groups. In general, prior volume of experience favored the high end of the scale with 59\% of SIM and $65 \%$ of LIVE participants having spent more than 11 hours on the simulator, and $54.5 \%$ of SIM and $50 \%$ of LIVE participants having repaired more than four lids in the past.

Demographics and experience data for expert participants are presented in -Table 2 . With the exception of a larger age range, demographic and experience data are largely similar between SIM and LIVE groups.

\section{Resident Improvement with Training (within-Group Analysis)}

Pre- and post-training metrics for SIM and LIVE groups were compared and are presented in -Table 3. There was a significant difference in margin approximation among the SIM group (BTR: 2.0 , PTR: $3.0 ; p=0.03$ ). SIM group metrics for residents were not significantly different from pre- to post-training evaluation in number of sutures, time to

Table 1 Resident group demographics and survey of prior simulation and eyelid repair experience

\begin{tabular}{|l|l|l|}
\hline \multicolumn{3}{|l|}{ Characteristics of resident oculoplastic training group } \\
\hline Demographics & $\begin{array}{l}\text { SIM training } \\
(\boldsymbol{n}=\mathbf{2 2})\end{array}$ & $\begin{array}{l}\text { LIVE training } \\
(\boldsymbol{n}=\mathbf{2 1})\end{array}$ \\
\hline Males & 11 & 13 \\
\hline Females & 11 & 8 \\
\hline Age & 22 & 19 \\
\hline $26-35$ & 0 & 2 \\
\hline $36-45$ & \multicolumn{5}{|l}{} \\
\hline Status & 18 & 17 \\
\hline 2nd year resident & 18 & 4 \\
\hline 3rd year resident & 4 & 1 \\
\hline Prior SIM use (hours) & \multicolumn{5}{|l|}{} \\
\hline $0-3$ & 6 & 6 \\
\hline $4-10$ & 3 & 10 \\
\hline $11-20$ & 9 & 3 \\
\hline$>20$ & 4 & 1 \\
\hline No. of prior eyelid repairs & 9 \\
\hline 0 & 1 & 7 \\
\hline $1-3$ & 9 & 3 \\
\hline $4-10$ & 9 & \\
\hline$>10$ & 3 & \\
\hline
\end{tabular}

Abbreviations: LIVE, live tissue; SIM, simulator. 
Table 2 Expert group demographics and survey of prior simulation and eyelid repair experience

\begin{tabular}{|c|c|c|}
\hline \multicolumn{3}{|c|}{ Characteristics of expert oculoplastic training group } \\
\hline Demographics & $\begin{array}{l}\text { SIM training } \\
(n=8)\end{array}$ & $\begin{array}{l}\text { LIVE training } \\
(n=8)\end{array}$ \\
\hline Males & 7 & 7 \\
\hline Females & 1 & 1 \\
\hline \multicolumn{3}{|l|}{ Age } \\
\hline $26-35$ & 1 & 3 \\
\hline $36-45$ & 3 & 1 \\
\hline $46-54$ & 3 & 2 \\
\hline $55-64$ & 1 & 1 \\
\hline$>65$ & 0 & 1 \\
\hline \multicolumn{3}{|l|}{ Status } \\
\hline Comprehensive & 0 & 1 \\
\hline Subspecialty-trained & 8 & 7 \\
\hline \multicolumn{3}{|l|}{ Prior SIM use (hours) } \\
\hline $0-3$ & 6 & 4 \\
\hline $4-10$ & 0 & 0 \\
\hline $11-20$ & 0 & 2 \\
\hline$>20$ & 2 & 2 \\
\hline \multicolumn{3}{|l|}{ No. of prior eyelid repairs } \\
\hline 0 & 0 & 1 \\
\hline $1-3$ & 0 & 3 \\
\hline $4-10$ & 3 & 1 \\
\hline$>10$ & 5 & 3 \\
\hline
\end{tabular}

Abbreviations: LIVE, live tissue; SIM, simulator.

completion, or tarsal plate reconstruction. There was no difference in successful completion of the exercise in either SIM or LIVE group when comparing pre- and post-training metrics.
LIVE group metrics were not significantly different from pre- to post-training evaluation in any metric studied. There was no significant difference in margin approximation in the LIVE group as was demonstrated in the SIM group.

\section{Resident LIVE versus SIM (between-Group Analysis)}

When comparing pre-training evaluation of SIM versus LIVE participants ( - Table 4 ), there was no significant difference noted in any of the measured metrics. When the same metrics were compared between groups following training, there was a significant difference in margin approximation (SIM: 3.0, LIVE: 2.0, $p=0.03$ ). Post-training evaluation of number of sutures, time to completion, and tarsal plate reconstruction failed to demonstrate significant differences. Overall, there was no significant difference in successful exercise completion when comparing SIM versus LIVE groups in post-training metrics.

\section{Expert Progression (within-Group Analysis)}

- Table 5 presents pre- and post-training metrics for expert participants within each SIM or LIVE group. SIM group metrics for expert participants were not significantly different from pre- to post-training evaluation in any metric studied.

Similarly, LIVE group metrics were not significantly different from pre- to post-training evaluation in any metric studied.

\section{Expert Progression (between-Group Analysis)}

Pre- and post-training metrics for SIM versus LIVE groups in expert participants are presented in -Table 6 .

\section{Subjective Participant Scores and Comments}

- Table 7 shows OTSL participant responses to the end of training survey. Responses were generally favorable toward the simulator modality. Seventy-nine percent of respondents felt the simulator was helpful in teaching skills, and $83 \%$ stated they would use the simulator to maintain skills. Fiftyfive percent of respondents felt the simulator was comparable for some or all of the tasks. However, when asked if the

Table 3 Within-group analysis of resident scoring metrics, baseline versus post-training, SIM and LIVE groups

\begin{tabular}{|c|c|c|c|c|c|c|}
\hline \multicolumn{7}{|c|}{ Resident group evaluation: within-group metrics } \\
\hline \multirow{2}{*}{$\begin{array}{l}\text { Measures } \\
\text { Median (IQR) }\end{array}$} & \multicolumn{2}{|l|}{$\operatorname{SIM}(n=22)$} & \multirow[t]{2}{*}{$p$-Value } & \multicolumn{2}{|l|}{ LIVE $(n=21)$} & \multirow[t]{2}{*}{$p$-Value } \\
\hline & Baseline & Post-training & & Baseline & Post-training & \\
\hline No. of sutures & $\begin{array}{l}5.0 \\
(4.0-6.3)\end{array}$ & $\begin{array}{l}5.0 \\
(5.0-6.0)\end{array}$ & 0.28 & $\begin{array}{l}6.0 \\
(5.0-6.0)\end{array}$ & $\begin{array}{l}5.0 \\
(5.0-6.0)\end{array}$ & 0.86 \\
\hline Time (s) & $\begin{array}{l}1,577 \\
(1,070-1,892)\end{array}$ & $\begin{array}{l}1,740 \\
(1,110-2,067)\end{array}$ & 0.77 & $\begin{array}{l}1,310 \\
(1,147-2,076)\end{array}$ & $\begin{array}{l}1,412 \\
(1,266-1,953)\end{array}$ & 0.50 \\
\hline Tarsal plate reconstruction ${ }^{a}$ & $\begin{array}{l}1.0 \\
(1.0-2.3)\end{array}$ & $\begin{array}{l}1.0 \\
(1.0-2.0)\end{array}$ & 0.48 & $\begin{array}{l}1.0 \\
(1.0-2.0)\end{array}$ & $\begin{array}{l}1.0 \\
(1.0-2.0)\end{array}$ & 0.99 \\
\hline Margin approximation ${ }^{a}$ & $\begin{array}{l}2.0 \\
(1.0-3.0)\end{array}$ & $\begin{array}{l}3.0 \\
(2.0-3.0)\end{array}$ & 0.03 & $\begin{array}{l}2.0 \\
(1.0-3.0)\end{array}$ & $\begin{array}{l}2.0 \\
(2.0-3.0)\end{array}$ & 0.26 \\
\hline Completed successfully & $54.7 \%(12)$ & $68.2 \%(15)$ & 0.54 & $38.1 \%(8)$ & $47.6 \%(10)$ & 0.76 \\
\hline
\end{tabular}

Abbreviations: IQR, interquartile range; LIVE, live tissue; SIM, simulator.

${ }^{\text {a}}$ Scale: 1 (poor) to 4 (excellent). 
Table 4 Between-group analysis of resident pre-training and post-training scoring metrics, SIM versus LIVE

\begin{tabular}{|c|c|c|c|}
\hline \multicolumn{4}{|c|}{ Resident group evaluation: between-group metrics } \\
\hline & $\operatorname{SIM}(n=22)$ & LIVE $(n=21)$ & $p$-Value \\
\hline \multicolumn{4}{|l|}{ Pre-training } \\
\hline No. of sutures required to close wound & $5.0(4.0-6.3)$ & $6.0(5.0-6.0)$ & 0.48 \\
\hline Time (s) & $1,577(1,070-1,892)$ & $1,310(1,147-2,076)$ & 0.90 \\
\hline Tarsal plate reconstruction $^{\mathrm{a}}$ & $1.0(1.0-2.3)$ & $1.0(1.0-2.3)$ & 0.86 \\
\hline Margin approximation $^{\mathrm{a}}$ & $2.0(1.0-3.0)$ & $2.0(1.0-3.0)$ & 0.45 \\
\hline Completed successfully & $54.5 \%(12)$ & $38.1 \%(8)$ & 0.36 \\
\hline \multicolumn{4}{|l|}{ Post-training } \\
\hline No. of sutures required to close wound & $5.0(5.0-6.0)$ & $5.0(5.0-6.0)$ & 0.85 \\
\hline Time (s) & $1,713(1,100-2,067)$ & $1,668(1,266-1,953)$ & 0.50 \\
\hline Tarsal plate reconstruction $^{\mathrm{a}}$ & $1.0(1.0-2.0)$ & $1.0(1.0-2.0)$ & 0.58 \\
\hline Margin approximation $^{\mathrm{a}}$ & $3.0(2.0-3.0)$ & $2.0(2.0-3.0)$ & 0.03 \\
\hline Completed successfully & $68.2 \%(15)$ & $47.6 \%(10)$ & 0.22 \\
\hline
\end{tabular}

Abbreviations: LIVE, live tissue; SIM, simulator.

${ }^{a}$ Scale: 1 (poor) to 4 (excellent).

Table 5 Within-group analysis of expert scoring metrics, baseline versus post-training, SIM and LIVE groups

\begin{tabular}{|c|c|c|c|c|c|c|}
\hline \multicolumn{7}{|c|}{ Oculoplastic expert group evaluation: within-group metrics } \\
\hline \multirow{2}{*}{$\begin{array}{l}\text { Measures } \\
\text { Median (IQR) }\end{array}$} & \multicolumn{2}{|l|}{$\operatorname{SIM}(n=8)$} & \multirow[t]{2}{*}{$p$-Value } & \multicolumn{2}{|l|}{$\operatorname{LIVE}(n=8)$} & \multirow[t]{2}{*}{$p$-Value } \\
\hline & Baseline & Post-training & & Baseline & Post-training & \\
\hline No. of sutures & $\begin{array}{l}5.0 \\
(3.3-5.0)\end{array}$ & $\begin{array}{l}5.0 \\
(4.0-5.0)\end{array}$ & 0.99 & $\begin{array}{l}5.0 \\
(4.3-5.8)\end{array}$ & $\begin{array}{l}5.0 \\
(5.0-6.0)\end{array}$ & 0.32 \\
\hline Time (s) & $\begin{array}{l}1,085 \\
(605-1,582)\end{array}$ & $\begin{array}{l}1,122 \\
(555-1,620)\end{array}$ & 0.67 & $\begin{array}{l}1,334 \\
(929-2,160)\end{array}$ & $\begin{array}{l}1,342 \\
(906-1,838)\end{array}$ & 0.09 \\
\hline Tarsal plate reconstruction $^{a}$ & $\begin{array}{l}1.5 \\
(1.0-4.0)\end{array}$ & $\begin{array}{l}2.0 \\
(1.0-4.0)\end{array}$ & 0.32 & $\begin{array}{l}1.5 \\
(1.0-2.0)\end{array}$ & $\begin{array}{l}1.5 \\
(1.0-3.8)\end{array}$ & 0.16 \\
\hline Margin approximation ${ }^{\mathrm{a}}$ & $\begin{array}{l}2.5 \\
(1.3-3.8)\end{array}$ & $\begin{array}{l}2.0 \\
(1.0-3.8)\end{array}$ & 0.16 & $\begin{array}{l}2.5 \\
(2.0-3.0)\end{array}$ & $\begin{array}{l}3.0 \\
(2.3-3.8)\end{array}$ & 0.32 \\
\hline Completed successfully & $62.5 \%(5)$ & $50 \%(4)$ & 0.99 & $62.5 \%(5)$ & $75 \%(6)$ & 0.99 \\
\hline
\end{tabular}

Abbreviations: IQR, interquartile range; LIVE, live tissue; SIM, simulator.

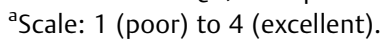

Table 6 Between-group analysis of expert pre-training and post-training scoring metrics, SIM versus LIVE

\begin{tabular}{|c|c|c|c|}
\hline \multicolumn{4}{|c|}{ Oculoplastic expert group evaluation: between-group metrics } \\
\hline & $\operatorname{SIM}(n=8)$ & $\operatorname{LIVE}(n=8)$ & p-Value \\
\hline \multicolumn{4}{|l|}{ Pre-training } \\
\hline No. of sutures required to close wound & $5.0(3.3-5.0)$ & $5.0(4.3-5.8)$ & 0.44 \\
\hline Time (s) & $1,085(605-1,582)$ & $1,334(929-2,160)$ & 0.20 \\
\hline Tarsal plate reconstruction $^{\mathrm{a}}$ & $1.5(1.0-4.0)$ & $1.5(1.0-2.0)$ & 0.57 \\
\hline Margin approximation $^{\mathrm{a}}$ & $2.5(1.3-3.8)$ & $2.5(2.0-3.0)$ & 0.88 \\
\hline Completed successfully & $62.5 \%(5)$ & $62.5 \%(5)$ & 0.99 \\
\hline \multicolumn{4}{|l|}{ Post-training } \\
\hline No. of sutures required to close wound & $5.0(4.0-5.0)$ & $5.0(5.0-6.0)$ & 0.13 \\
\hline Time (s) & $1,122(555-1,620)$ & $1,342(906-1,838)$ & 0.44 \\
\hline Tarsal plate reconstruction ${ }^{\mathrm{a}}$ & $2.0(1.0-4.0)$ & $1.5(1.0-3.8)$ & 0.80 \\
\hline Margin approximation $^{a}$ & $2.0(1.0-3.8)$ & $3.0(2.3-3.8)$ & 0.33 \\
\hline Completed successfully & $50 \%(4)$ & $75 \%(6)$ & 0.61 \\
\hline
\end{tabular}

Abbreviations: LIVE, live tissue; SIM, simulator.

${ }^{\mathrm{a} S}$ Scale: 1 (poor) to 4 (excellent). 
Table 7 OTSL participant survey responses

\begin{tabular}{|l|l|l|l|l|}
\hline OTSL survey responses & Number of OTSL survey respondents $(\boldsymbol{n}=29)$ \\
\hline Question & Yes & Somewhat & No & No response \\
\hline & $\begin{array}{l}16 \\
(55 \%)\end{array}$ & $\begin{array}{l}9 \\
(31 \%)\end{array}$ & $\begin{array}{l}4 \\
(14 \%)\end{array}$ & 0 \\
\hline $\begin{array}{l}\text { Was the simulator comparable to animal tissue for } \\
\text { all/some of the tasks? }\end{array}$ & $\begin{array}{l}23 \\
(79 \%)\end{array}$ & $\begin{array}{l}6 \\
(21 \%)\end{array}$ & 0 & 0 \\
\hline $\begin{array}{l}\text { Was simulator training helpful in teaching all/some } \\
\text { of the skills? }\end{array}$ & $\begin{array}{l}12 \\
(41 \%)\end{array}$ & $\begin{array}{l}6 \\
(21 \%)\end{array}$ & $\begin{array}{l}11 \\
(38 \%)\end{array}$ & 0 \\
\hline $\begin{array}{l}\text { Can simulator training substitute animal tissue } \\
\text { training on all/some of the metrics? }\end{array}$ & $\begin{array}{l}24 \\
(83 \%)\end{array}$ & - & $\begin{array}{l}4 \\
(14 \%)\end{array}$ & 1 \\
\hline $\begin{array}{l}\text { Are you likely to use the simulator, if it were avail- } \\
\text { able, to maintain your skills? }\end{array}$ & & \\
\hline
\end{tabular}

Abbreviation: OTSL, Ocular Trauma Surgery Laboratory.

simulator could substitute for animal tissue on some or all metrics, $41 \%$ responded favorably, while $59 \%$ collectively replied "somewhat" or "no."

\section{Discussion}

As advancements in technology allow ever-increasing accuracy in simulation of real-life surgical situations, continual evaluation of training methodology is of the utmost importance. Force readiness in today's combat environment necessitates well-trained ophthalmic surgeons capable of handling large volumes of complicated eye trauma. In an effort to continually improve readiness, ophthalmologists need to have reliable, ethical, reproducible, and measureable methods to practice complex surgical repair. In this study, we have demonstrated that simulation technology is noninferior to live animal tissue for training ophthalmologists in marginal eyelid laceration repair.

With the exception of marginal approximation in the SIM group, within-group analysis among resident participants in the OTSL course demonstrated no significant difference in metric and task completion within SIM or LIVE groups when pre- and post-training scores were compared.

Between-group analysis of SIM versus LIVE training when comparing pre- and post-training scores for resident course participants demonstrated no significant difference between metric and task completion scoring, with exception of margin approximation.

These findings demonstrate efficacy of SIM training for marginal eyelid laceration repair when viewed in light of results obtained for the gold standard LIVE training. Indeed, our results even suggest possible superiority in the marginal approximation metric. Given our small sample size, it is possible further study with larger numbers of participants may yield additional data supporting metric-based superiority of SIM training. However, at this stage, we can reasonably conclude that SIM training is noninferior to LIVE training for marginal eyelid laceration repair among novice surgeons, and is therefore warranted in its continued use and development.

Within-group analysis of SIM and LIVE training, and between-group analysis of SIM versus LIVE training, among board-certified ophthalmologists and oculoplastic experts demonstrated no significant difference when comparing pre- and post-training metrics and task completion. Again, these results are supportive of continued use and development of simulated training systems for marginal eyelid repair. Given the presumed high level of surgical skill among comprehensive ophthalmologists and oculoplastic experts, significant pre- and post-training scoring differences are not expected. As LIVE training is the gold standard, our results show that SIM training is not significantly different as a training methodology when limitations in basic surgical skill are eliminated with expert participants.

Interestingly, among both expert and resident groups, tarsal plate reconstruction and margin approximation scores were low. Indeed, tarsal plate approximation was never graded as good or excellent on the four-point scoring metric in either the resident or expert group. This may reflect inadequacy of the porcine model as the final test model, though it remains the gold standard. Anatomical variation between species may account for this inadequacy, even if the tissue characteristics of porcine skin are more similar to human. Given these concerns for porcine to human fidelity, future studies could examine outcomes with the final test model as the mannequin lid, which is designed to be more anatomically correct, regardless of other tissue characteristics.

OTSL participants largely reported a positive experience with simulator training, and a desire for its continued use in skill maintenance. Among the survey questions asked, the two most positively responded to questions were "Was simulator training helpful in teaching all/some of the skills?" and "Are you likely to use the simulator, if it were available, to maintain your skills?" Participants' response was less enthusiastic when asked about simulator training as a substitute for animal training, and the comparable quality of simulator tissue to animal tissue. Indeed, 59\% of respondents stated that simulator training was somewhat or not able to substitute for animal training.

These results indicate that while simulator technology needs improvement for more lifelike tissue and subsequent use as a substitute for animal training, simulator technology is viewed favorably and likely to have continued use. As both 
simulator and artificial tissue technologies continue to improve, their ability to substitute for traditional animalbased training is expected to improve as well. Given the desire to move away from animal-based training, it is encouraging that learners are enthusiastic about simulator training, and willing to incorporate its continued use for their own skill maintenance.

Limitations for this study include small sample size, isolated participant demographics, individual participant variability in surgical skillset, and narrow window of participant follow-up. Sample size was relatively limited both in participants and participant affiliation. This is a result of OTSL course limitations in number of possible participants, and the restricted nature of a military training environment. Indeed, given the small sample size of the staff physicians taking part in the training, there was not enough statistical power to derive correlation of expert progression in measured metrics as compared with resident progression. To achieve the power necessary to provide a statistically significant result, sample size would need to approach approximately 400 , not feasible for a study this size. Individual variability in surgical skills was attempted to be controlled against in initial grouping of participants according to their time to completion using a median split of the group's baseline "time required to close wound." While this should have cut down on baseline skill variability interference with results, it is still possible it may have had an effect. Finally, longer term follow-up of participants (months to years) following training could give insight into maintenance of skills learned, as well as long-term perceptions of simulation training.

Addressing these limitations would involve primarily a larger scope of study. Increased institutional participation, both military and civilian, would increase participant sample size and improve heterogeneity of sample demographics.

As the ultimate goal of any ophthalmic training program is to enhance patient safety and improve outcomes, task performance should be standardized and ideal simulator technology that provides realistic tissue characteristics, measurable and reproducible trainee tasks, and formative feedback should become the standard in training.

\section{Meeting Presentation}

Portions of this material were presented at the annual meetings of the Military Health System Research Symposium, Orlando, Florida, August 2016 and 2017.

\section{Disclaimer}

The opinions or assertions contained herein are the private ones of the author and are not to be construed as official or reflecting the views of the Department of Defense, the Uniformed Services University of the Health Sciences, or any other agency of the U.S. Government.

\section{Funding}

This study is funded by the U.S. Army Medical Research and Materiel Command Award \#TL100010.

Conflict of Interest

None declared.

\section{References}

1 Centers for Disease Control and Prevention (CDC). Rapid assessment of injuries among survivors of the terrorist attack on the World Trade Center-New York City, September 2001. MMWR Morb Mortal Wkly Rep 2002;51(01):1-5

2 Mines M, Thach A, Mallonee S, Hildebrand L, Shariat S. Ocular injuries sustained by survivors of the Oklahoma City bombing. Ophthalmology 2000;107(05):837-843

3 Weichel ED, Colyer MH. Combat ocular trauma and systemic injury. Curr Opin Ophthalmol 2008;19(06):519-525

4 Pfaff AJ. Pig eyelid as a teaching model for eyelid margin repair. Ophthal Plast Reconstr Surg 2004;20(05):383-384

5 Akhtar KS, Chen A, Standfield NJ, Gupte CM. The role of simulation in developing surgical skills. Curr Rev Musculoskelet Med 2014;7 (02):155-160

6 Samia H, Khan S, Lawrence J, Delaney CP. Simulation and its role in training. Clin Colon Rectal Surg 2013;26(01):47-55

7 DOD Instruction 3216.01. 2010; Section 4b

8 Pokroy R, Du E, Alzaga A, et al. Impact of simulator training on resident cataract surgery. Graefes Arch Clin Exp Ophthalmol 2013;251(03):777-781

9 McCannel CA, Reed DC, Goldman DR. Ophthalmic surgery simulator training improves resident performance of capsulorhexis in the operating room. Ophthalmology 2013;120(12):2456-2461 